\title{
Development and Characterization of Post-consumer Rubber Tire Powder, High Density Polyethylene and Ethylene-octene-1Copolymer Ternary Mixtures
}

\author{
Kelly Cristina de Castro, Adriane Bassani Sowek, Luís Antonio Pinheiro \\ Department of Materials Engineering, State University of Ponta Grossa - UEPG, Ponta Grossa, PR, Brazil \\ Luiz Antonio Pessan, Sebastião Vicente Canevarolo \\ Department of Materials Engineering, Federal University of São Carlos - UFSCar, São Carlos, SP, Brazil
}

\begin{abstract}
Scrap tires are considered a type of waste that litters landfills and the environment in general. Due to its chemically cross-linked structure, this material cannot be recycled by conventional processes because it does not melt. This work examined the production of polymeric composites using high density polyethylene (HDPE) filled with rubber tire powder (RTP). Ethylene-octene-1 copolymer (C2C8), an elastomeric material, was also added to improve the mechanical properties. Morphological analysis showed a good interfacial adhesion when $\mathrm{C} 2 \mathrm{C} 8$ is added to the mixture. Raman spectroscopy coupled to optical microscopy revealed that the HDPE phase encapsulated the rubber tire particles. The mixtures containing $\mathrm{C}_{2} \mathrm{C}_{8}$ and RTP presented lower ultimate tensile strength and elastic modulus, but the impact strength of the binary and ternary mixtures was much higher than that of neat HDPE.
\end{abstract}

Keywords: High density polyethylene, ethylene-1-octene copolymer, rubber tire powder, mechanical properties.

\section{Introduction}

The last decade has seen a rapid increase in the world's vehicle fleet, which has resulted in a proportional increase in the consumption of rubber tires. Although this scenario has benefited tire manufacturers, it has also led to extensive environmental littering and its consequent impacts ${ }^{[1-3]}$. This type of waste disposal represents three significant risks: high probability of burning due to the presence of flammable oils in tire composition; the presence of toxic chemicals that can undergo leaching, which causes groundwater contamination; and depending on how they are discarded, scrap tires can accumulate rainwater, thus serving as breeding sites for disease-carrying insects ${ }^{[4]}$.

Tires are bulky, slow to decompose, and difficult to recycle and reuse $\mathrm{e}^{[3,4]}$. The steel wire structure is difficult to separate from the others parts and the presence of macromolecular crosslinks renders the material infusible. Aiming to minimize these problems, the National Council of the Environment (CONAMA) a Brazilian bureau devoted to monitor actions concerned to environment, in its Resolution 416/2009, established a goal that, for each new tire sold in the after-sales market, the tire manufacturers and dealers must ensure the proper disposal of one unserviceable tire.

The most common ways to recycle and reuse rubber tires include retreading, remolding, burning to recover their energy content, devulcanization, microbial disintegration, and mixing with other materials such as asphalt $t^{[4-8]}$. When rubber tire is ground it can be added to polymeric matrix to produce composites. This is considered an interesting strategy for reusing this waste because the process is relatively simple and involves only mechanical mixing ${ }^{[9,10]}$. However, the incorporation of rubber tire powder (RTP) can result in materials with poor mechanical properties due to the lack of interfacial adhesion between polymer and $\mathrm{RTP}^{[9-12]}$. Several techniques are employed to improve the interfacial properties between these components: partial devulcanization of rubber tire, treatment with peroxides to create reactive sites in the RTP surface, functionalization of the waste tire rubber, and the addition of non-reactive copolymers with chemical affinity with composite components $^{[9,13-17]}$.

To improve the interaction between the phases in LDPE and RTP, Ouyang et al. ${ }^{[12]}$ studied several compatibilizers. The mechanical properties were improved with maleic anhydride grafted polyethylene (PE-g-MA) and grafted ethylene-octene-1 copolymer (POE-g-MA) as compatibilizers. Colom et al. ${ }^{[15]}$ studied the influence of pretreatments and RTP particle size on a mixture with high density polyethylene (HDPE) and found that treatment with acid improves the mechanical bonding between phases and that small particles provided the best performance. In another investigation, Colom et al. ${ }^{[15]}$ observed that the addition of low concentrations of rubber tire treated with sulfuric acid to an HDPE matrix improved its mechanical properties and performance. Naskar et al. ${ }^{[18]}$ studied mixtures of HDPE homopolymer, EPDM elastomer, RTP, and dicumyl peroxide (DCP). They concluded that the EPDM encapsulated the rubber tire particles dispersed in the HDPE matrix. They also recommended that $50 \%$ of EPDM be replaced by rubber tire powder. This replacement does not affects the final properties of the material and favors reuse of the tire. Grigoryeva et al. ${ }^{[19]}$ observed the interface of elastomeric thermoplastic mixtures with a view to improving their final mechanical properties. According to these authors, in a ternary mixture of thermoplastic, elastomer and filler, the elastomer is expected to

Corresponding author: Luís Antonio Pinheiro, Department of Materials Engineering, State University of Ponta Grossa - UEPG, General Carlos Cavalcanti Avenue, 4748, Zip Code 84030-900, Ponta Grossa, PR, Brazil, e-mail: lapinheiro@uepg.br 
encapsulate the filler particles, keeping them apart from the polymeric matrix. They stated that this encapsulation, together with compatibilization strategies, improves the mechanical properties of these mixtures.

This work involved a study of ternary mixtures of HDPE, RTP and ethylene-co-1-octene, their morphology and the impact of the components concentration in the mechanical properties. Besides, depends upon the performance of the mixtures, the objective of this study was to develop an alternative for the reuse of scrap tires.

\section{Experimental}

\section{Materials}

The polymer used as matrix was high density polyethylene (HDPE) commercialized under the trade name IE-59 U3, manufactured by Braskem S.A., with a melt flow index (MFI) of $5 \mathrm{~g} / 10 \mathrm{~min}\left(190{ }^{\circ} \mathrm{C}, 2.16 \mathrm{~kg}\right)$. The rubber tire powder (RTP) was supplied by the company Presidente Recapagem and was originated from the truck tire retreading process. Ethylene and octene-1 copolymer $\left(\mathrm{C}_{2} \mathrm{C}_{8}\right)$, under the trade name Engage 8402, was supplied by Dow Brasil. This copolymer possesses a MFI of $30.0 \mathrm{~g} / 10 \mathrm{~min}$ and a density of $0.902 \mathrm{~g} / \mathrm{cm}^{3}$.

\section{Rubber tire characterization}

The ground rubber tire was sifted through a 32 mesh sieve to separate the smaller rubber particles from the larger ones and from metal and textile wastes. The sifted material was characterized in a CILAS 920 particle size analyzer to determine its particle size distribution curve. Since the density of RTP is similar to that of water, the rubber particles were dispersed in isopropyl alcohol for this test.

A thermogravimetric analysis (TGA) was performed in a SDT 2960 simultaneous DSC-TGA (TA Instruments) to verify the weight loss of samples and determine the nonvolatile solids content in RTP. To this end, the samples were heated from room temperature to $600{ }^{\circ} \mathrm{C}$ at $10^{\circ} \mathrm{C} / \mathrm{min}$ in a nitrogen atmosphere.

\section{Preparation of the composites}

The materials were processed in a Werner \& Pfleiderer ZSK-30 intermeshing twin screw extruder equipped with gravimetric feeders. Twin screw extruders are normally used for blending materials to obtain a well dispersed composite. The temperature profile was $240{ }^{\circ} \mathrm{C}$ in all the five heating zones and the die, the overall throughput was kept constant at $5 \mathrm{~kg} / \mathrm{h}$, and the screw speed was set at $100 \mathrm{rpm}$. The screw profile is shown in Figure 1. The extruder is designed with a melt seal in the first third of the screw to ensure complete melting of polymer. The device contains other sets of kneading disks to disperse and distribute the mixture components in order to break RTP agglomerates and ensure composite's homogeneity. All the components were fed into the main hopper at the entry of the extruder barrel. The compositions used in this work is given in Table 1.

Each component had its concentration changed in 10 units to provide another composition. Immediately after extrusion, the mixtures were pelletized and the pellets molded in a Boy 55M injection molding machine. The temperature profile for injection was 200, 220, 220, and $240^{\circ} \mathrm{C}$. The mold was kept at room temperature by a water circulation system.

\section{Morphological characterization}

The samples' morphology was analyzed in a Shimadzu SSX 550 scanning electron microscope (SEM) at 5kV. Prior to this analysis, the samples were cryogenically fractured and their surfaces were gold coated.

Samples were also analyzed in a SENTERRA Bruker FT-Raman spectrometer coupled to an optical microscope. For this analysis, samples were cut with a microtome into $60 \mathrm{~mm}$ thin slices. The exciting radiation was $532 \mathrm{~nm}$, and a laser power of $5 \mathrm{~mW}$ was applied for pure RTP and of $20 \mathrm{~mW}$ for the other materials and composites. The image acquisition time was $20 \mathrm{~s}$ for pure RTP and $5 \mathrm{~s}$ for the other materials.

\section{Mechanical properties}

Tensile essays were performed in an AG-I Shimadzu universal testing machine with $10 \mathrm{kN}$ load cell capacity. Thereafter, elastic modulus (EM) and ultimate tensile strength (UTS) were determined based on the ASTM D-638 standard. All the tests were performed at $5 \mathrm{~mm} / \mathrm{min}$.

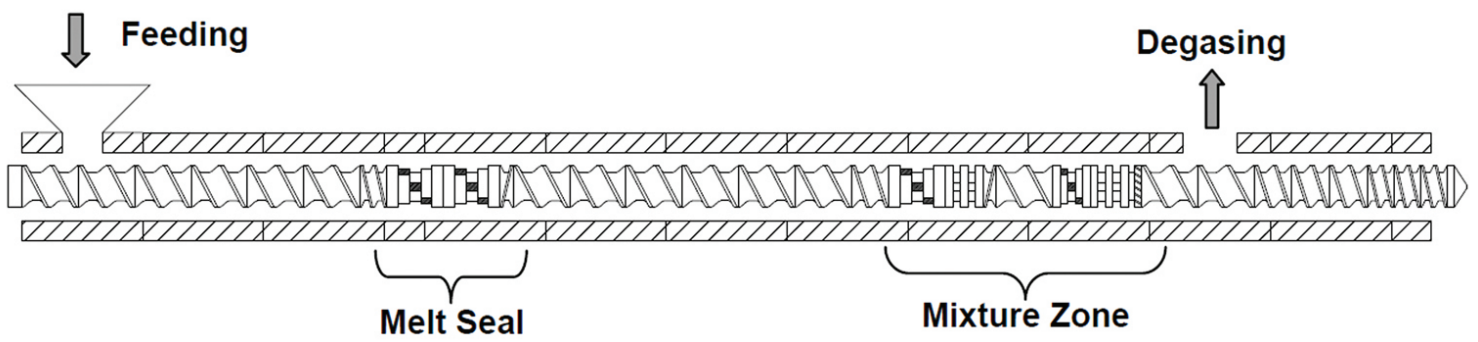

Figure 1. Screw profile used for processing the formulations.

Table 1. Compositions used in this work. Concentrations in percent (\%).

\begin{tabular}{|c|c|c|c|c|c|c|c|c|c|c|c|c|c|c|}
\hline Composition & 1 & 2 & 3 & 4 & 5 & 6 & 7 & 8 & 9 & 10 & 11 & 12 & 13 & 14 \\
\hline HDPE & 100 & 90 & 90 & 80 & 80 & 70 & 70 & 70 & 70 & 60 & 60 & 60 & 60 & 60 \\
\hline $\mathrm{C} 2 \mathrm{C} 8$ & 0 & 0 & 10 & 0 & 10 & 0 & 10 & 20 & 30 & 0 & 10 & 20 & 30 & 40 \\
\hline RTP & 0 & 10 & 0 & 20 & 10 & 30 & 20 & 10 & 0 & 40 & 30 & 20 & 10 & 0 \\
\hline
\end{tabular}


Fifteen samples of each composition were tested, except pure HDPE, of which 10 samples were tested.

Izod impact tests were performed in a CEAST pendulum impact testing machine. For this test, all the samples had a $2.5 \mathrm{~mm}$ deep notch. The procedure was performed according to the ASTM D-256 standard, and 15 samples of each composition, including pure HDPE, were tested.

\section{Results and Discussion}

\section{Analysis of the rubber tire powder (RTP)}

The RTP sifted through the 32 mesh sieve was analyzed to determine its particle size distribution curve. The average particle size was $143.64 \mathrm{~mm}$. Araújo et al. ${ }^{[20]}$ studied the influence of rubber particle size on polymeric composites and found that the final mechanical properties of particles in the range of 30 to 80 mesh do not change significantly. The average particle size observed in our work was considered within the acceptable range of particle sizes according to other studies, which found that the optimum particle size is smaller than $200 \mathrm{~mm}^{[20]}$. Others researchers stated that it is possible to obtain acceptable mechanical properties with particles from up to $250 \mu \mathrm{m}$, but these properties decline drastically above $500 \mathrm{~mm}^{[21]}$. FerrerGiménez et al. ${ }^{[22]}$ studied the influence of rubber tire particle size on the morphology of composites and found that very large particles do not have good filler ability and strongly influence the mechanical properties when rubber powder is added to the elastomeric matrix.

The thermogravimetric results of the RTP (Figure 2) showed that, in the vicinity of $500{ }^{\circ} \mathrm{C}$, weight loss reached $63.48 \%$. The remaining $36.52 \%$ was attributed to nonvolatile solids, which consisted almost entirely of carbon black filler. The weight loss of rubber tire powder by thermogravimetry is caused by the release of moisture and volatile compounds due to the thermal decomposition of rubbery components.

\section{Morphological characterization}

The objective of SEM analyses is to examine the degree of dispersion and distribution of RTP in the HDPE matrix. Figure 3 illustrates the morphology of a 70\% HDPE/ 30\% RTP mixture. The darker area corresponds to HDPE and the lighter areas to RTP.

This micrograph indicates that the extrusion process dispersed and distributed the RTP efficiently in the HDPE matrix. It was also analyzed the blend between HDPE and $\mathrm{C} 2 \mathrm{C} 8$. Prior to this analysis, $\mathrm{C} 2 \mathrm{C} 8$ phase was extracted with xylene for $8 \mathrm{~h}$ at $40^{\circ} \mathrm{C}$. The images are not shown here, but they do not revealed any hole where possible have could a C2C8 particle, and this fact was attributed to a miscibility of both polymers, showing that this mixture is homogeneous.

Figure 4 shows the morphology of a ternary $60 \%$ HDPE/ 30\% C2C8/ 10\% RTP. One could figure out that $\mathrm{C} 2 \mathrm{C} 8$ is placed in the interface between HDPE and RTP, but this is not a feature observed by SEM images.

The composition at the interface was analyzed by Raman spectroscopy coupled to optical microscopy. This

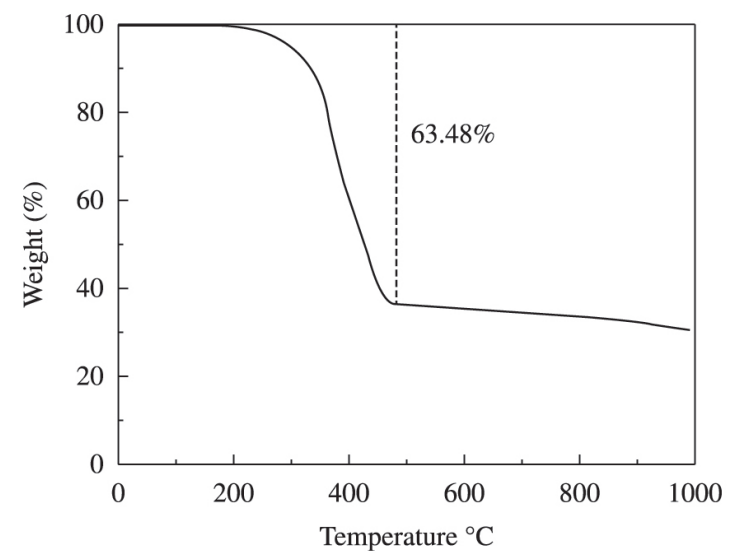

Figure 2. Thermogravimetric analysis of tire rubber powder.

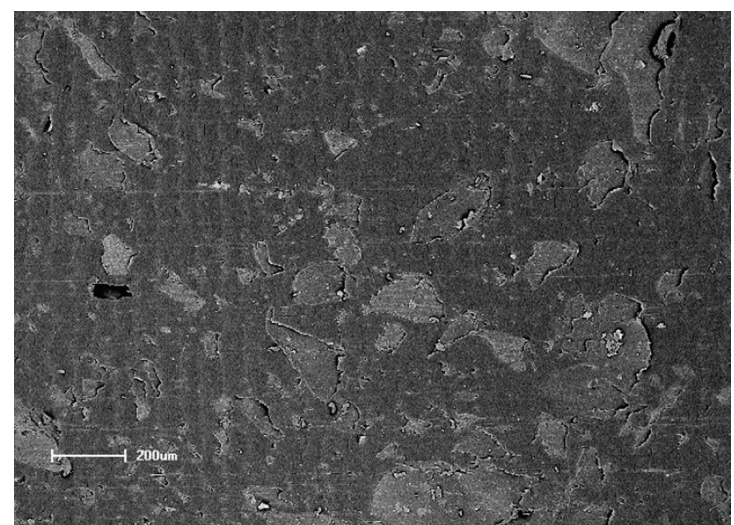

Figure 3. SEM micrograph of the sample of 70/30 (\%) HDPE/RTP.

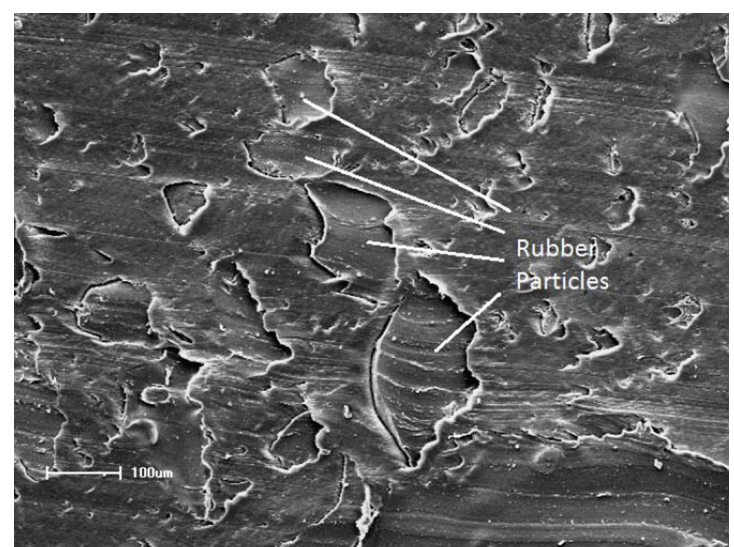

Figure 4. SEM micrographs of the HDPE/C2C8/RTP 60/30/10 (\%).

enables the acquisition of Raman spectra of a specific region in the microstructure. Figure 5 shows a rubber particle (dark spot) and four plus signals around it, pointing the location where the spectra were collected. On the other hand, Figure 6 shows the result for this mapping and the spectra for neat materials. The pure materials were first analyzed in order to acquire their respective spectra. HDPE spectrum shows peaks in the region of low frequency, from 1.000 to $1.600 \mathrm{~cm}^{-1}$, related to vibrate modes of C-C bond, meaning that there were distortions in this polymeric bond. In the spectrum of this polymer it is also verified peaks in the 
region of high frequency $\left(2500-3200 \mathrm{~cm}^{-1}\right)$, attributed to methylenic group $\left(-\mathrm{CH}_{2}-\right)$, characteristic of polyethylene ${ }^{[23]}$. C2C8 copolymer presents high similarity with HDPE, just because ethylene monomers take part of its structure; however, its spectrum reveals some differences due to the presence of octene 1 units, mainly in the region of low frequencies, from 400 to $800 \mathrm{~cm}^{-1}$. The peaks in this range are related to aliphatic carbon-carbon bonds. On the other hand, for the RTP there are peaks at $1330 \mathrm{~cm}^{-1}$, due to C-SO bonds, at $1600 \mathrm{~cm}^{-1}$ related to C-S bonds, in the range of 2900 and $3100 \mathrm{~cm}^{-1}$ due to $\mathrm{C}-\mathrm{H}$ bonds, and $3500 \mathrm{~cm}^{-1}$ due to S-H bonds ${ }^{[23]}$.

After the analysis of neat materials, it was carried out a mapping around a rubber particle in order to verify the material present in its interface. The same analysis was repeated for others compositions and because they presented the same results they are not going to be showed here. The spectra related to the markers around the RTP particles are

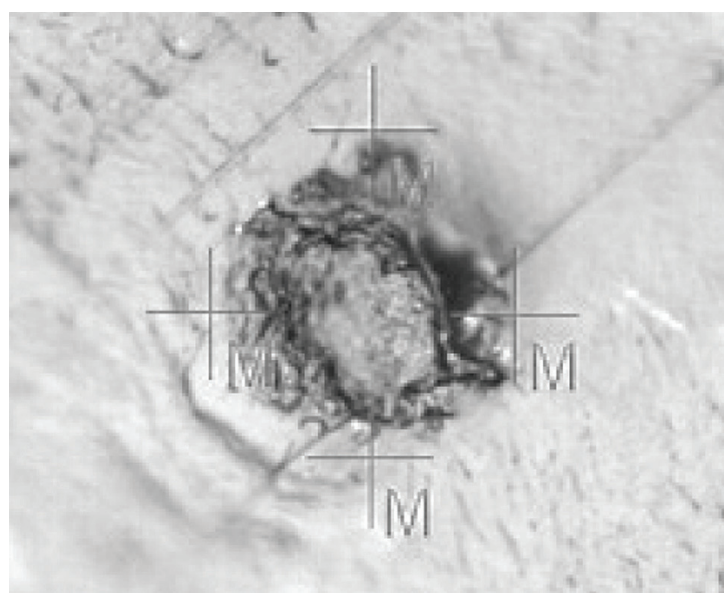

Figure 5. Optical microscopy coupled to Raman spectrometer of a RTP particle in a olefinic matrix. similar to the HDPE one. The results lead to the conclusion that HDPE matrix encapsulates rubber particles instead of $\mathrm{C} 2 \mathrm{C} 8$. Thus, the ethylene-octene 1 copolymer does not act in the HDPE/ RTP interface. According to some works reported in literature ${ }^{[19,24]}$ it is expected that elastomeric component envelops the dispersed phase and put itself up in the interface, but it did not happen in our study. This is explained by the fact that HDPE and $\mathrm{C} 2 \mathrm{C} 8$ have great chemical affinity and it makes them miscible, according to SEM micrographs. Due to this combination between them, $\mathrm{C} 2 \mathrm{C} 8$ are prone to be dispersed in HDPE matrix instead of being segregated from it and being located at the interface with RTP.

\section{Mechanical properties}

Mechanical properties analyzed were ultimate tensile strength, elastic modulus, and impact strength. In order to verify similarities among samples, statistical Tukey test was performed, at $5 \%$ level. Thus, data with same letter can be considered similar with $95 \%$ confidence.

Figure 7 presents the results for the ultimate tensile strength (UTS) that is the maximum value of stress observed in a tensile test while a sample is stretched. For the binary mixtures, the UTS values decrease when $\mathrm{C} 2 \mathrm{C} 8$ and RTP are individually added to HDPE matrix comparing with this polymer in the neat form, but the latter gives rise to greater reduction. Pure $\mathrm{C} 2 \mathrm{C} 8$ has lower UTS than HDPE, which is a feature of several elastomeric materials, and contributes to decrease UTS magnitude for HDPE/C2C8 blends, even though they produce a homogeneous mixture. The addition of RTP decreases UTS values because of the lack of adhesion between it and HDPE. The ternary mixtures present intermediate values between binary mixtures, $i$. e., the high the concentration of $\mathrm{C} 2 \mathrm{C} 8$ higher UTS value; when RTP is added these amounts decreased. Despite this behavior, the ternary mixtures present lower UTS values than neat HDPE.

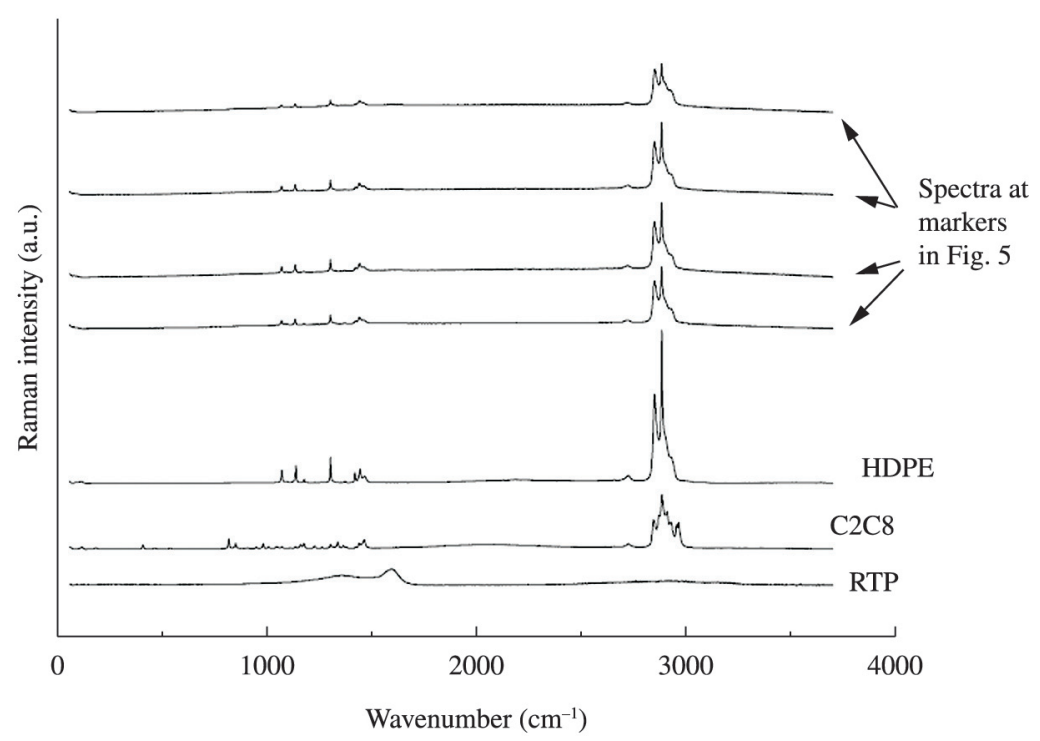

Figure 6. Raman spectra for neat materials and mixture 60/30/10 (HDPE / C2C8 / RTP). 
For compositions with constant HDPE concentration, Tukey test showed that there is no statistical significance between the formulations, unlike for HDPE/ C2C8 blends below, which showed higher UTS values for a set with the same HDPE concentration.

Figure 8 shows the influence of the components concentration on elastic modulus for the mixtures, which is a measurement of the material's stiffnes, i. e., the ease with which the material is deformed. For the HDPE/ C2C8 blend there are lower values of elastic modulus because the elastomeric copolymer in its neat form has lower values of elastic modulus than neat HDPE, contributing to decrease magnitude of this property when added to the mixture. The same behavior is observed form the HDPE and untreated RTP binary mixtures due to the poor interfacial adhesion between the components. This behavior was also observed by Colom et al. ${ }^{[16]}$, who studied the mixtures between HDPE and rubber tire powder and observed a decrease in elastic modulus with the increase on rubber content, a common result for mixtures between semicrystalline polymers and rubber powder. Comparing both components in the binary mixtures, RTP does not decrease elastic modulus values as much as $\mathrm{C} 2 \mathrm{C} 8$ because of the presence of carbon black that acts like reinforcement. As observed for UTS, the ternary mixtures have intermediate values between the binary mixtures, but the decrease in its values is not abrupt when $\mathrm{C} 2 \mathrm{C} 8$ is added to a previous HDPE/RTP mixture, showing that the presence of this elastomeric copolymer can compatibilize the mixtures due to its affinity with HDPE. Despite this observations, Tukey test revealed differences only for neat HDPE and for the HDPE/RTP mixtures above $70 \%$ HDPE.

Impact strength (IS) is the energy expended to fracture a sample per length or area and can be also related to toughness. Figure 9 shows the results of impact strength for all compositions produced. Neat HDPE presented lower IS compared with binary mixtures with $\mathrm{C} 2 \mathrm{C} 8$. The addition of $10 \%$ of this copolymer is enough to increase IS from 100 to $510 \mathrm{~J} / \mathrm{m}$. The continuous increase in its concentration in the mixture keep rising the IR. This significant increase in impact strength is attributed to the presence of octane-1 comonomer, which grants elastomeric feature to the composite and makes it able to absorb high impact energy and increase toughness. Besides this, there is the chemical affinity with HDPE which makes the blend between them to be miscible, as showed by SEM images. This result agrees with that showed by Lotti et al. ${ }^{[24]}$, where polypropylene/ $\mathrm{C} 2 \mathrm{C} 8$ blends were studied, i. e., the increase in the concentration of this copolymer increases the blend toughness.

On the other hand, the results for the binary mixtures between HDPE and RTP show that the addition of rubber tire powder gives rise to a slight decrease in IS for 10 and $20 \%$. This is attributed to the lack of good interfacial adhesion between phases, making interface a weak site in the composite structure. Despite this behavior, and a slight increase in IS for 30 and $40 \%$, superior to the impact strength for neat HDPE. There is the lack of adhesion stated previously, but as the content of RTP increases, it also provides elastomeric feature to the composite, increasing impact strength. This is an important result because it

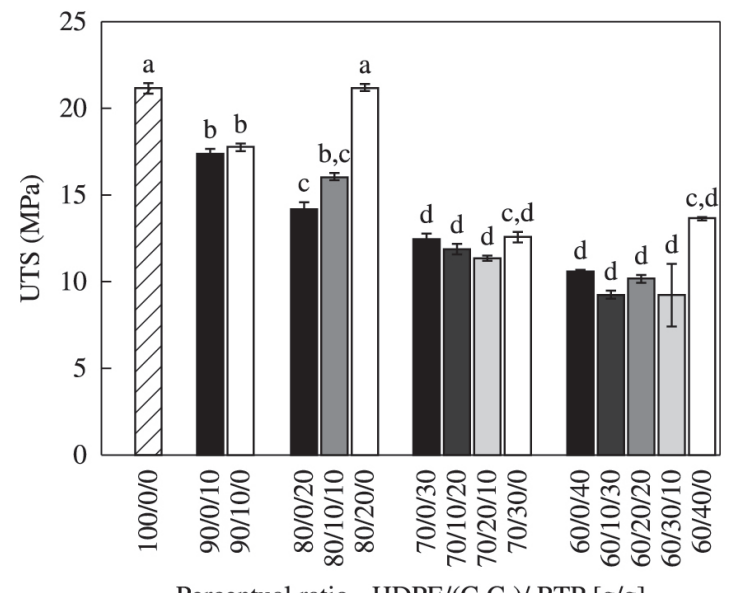

Percentual ratio - HDPE $/\left(\mathrm{C}_{2} \mathrm{C}_{8}\right) / \mathrm{RTP}[\mathrm{g} / \mathrm{g}]$

Figure 7. Ultimate tensile strength. Letters $a, b, c$, and $d$ are related with the similarity degree according to Tukey test, at $95 \%$ of confidence.

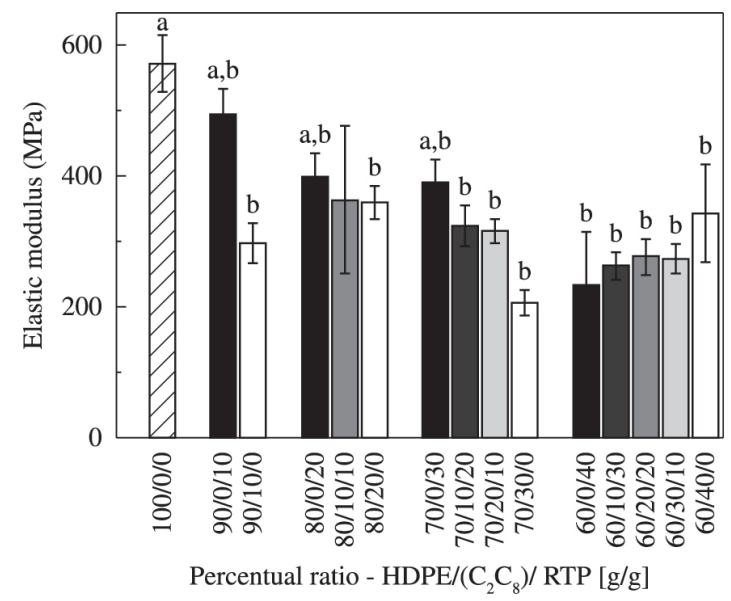

Figure 8. Elastic modulus. Letters $a$ and $b$ are related with the similarity degree according to Tukey test, at $95 \%$ of confidence.

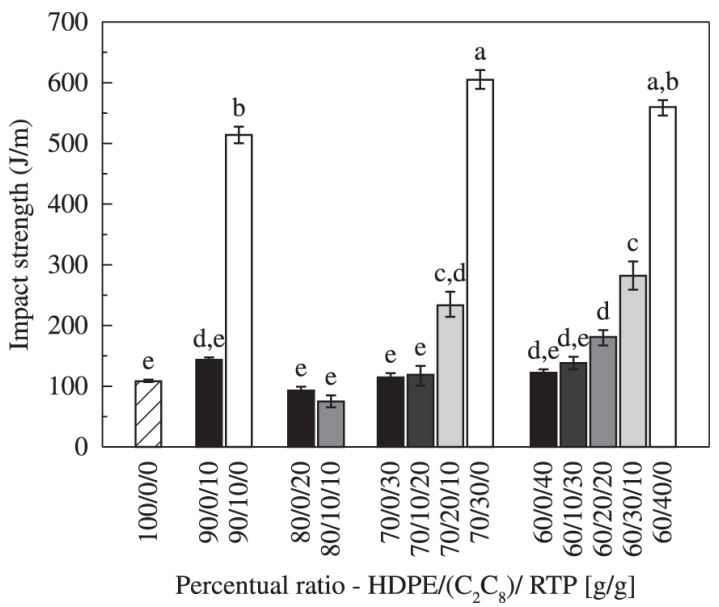

Figure 9. Impact strength (IZOD). Letters $a, b, c, d$, and $e$ are related with the similarity degree according to Tukey test, at $95 \%$ of confidence. 
shows that it is possible to add great concentration of rubber particles in HDPE matrix without any abrupt variation on impact behavior.

Figure 9 also shows that the values of IS for the ternary mixtures were intermediate between the binary mixtures with $\mathrm{C} 2 \mathrm{C} 8$ copolymer and RTP. The addition of $10 \% \mathrm{C} 2 \mathrm{C} 8$ gives rise to a little increase in mixture toughness and additional increases in this elastomeric component keeps enhancing this feature. For example, the compositions $70 \% \mathrm{HDPE} / 20 \% \mathrm{C} 2 \mathrm{C} 8 / 10 \% \mathrm{RTP}$ and $60 \% \mathrm{HDPE} / 30 \%$ $\mathrm{C} 2 \mathrm{C} 8 / 10 \%$ presented an increase of 120 and $210 \%$ in IR, respectively, compared with pure HDPE. In fact, it means that the addition of $\mathrm{C} 2 \mathrm{C} 8$ in the mixture yields a synergistic effect with HDPE matrix. This behavior is attributed to their good chemical interaction, which indeed also makes its blend miscible according to SEM micrographs. In spite of not being properly at the interface, as observed by Raman analysis, the addition of $\mathrm{C} 2 \mathrm{C} 8$ improved the impact strength because it enhanced the resistence of HDPE matrix. It is also possible that interfacial properties due to the addition of $\mathrm{C} 2 \mathrm{C} 8$ is responsible for the better adhesion of RTP in the polymeric matrix.

In a statistical overview, Tukey test showed that this property presented the most significant variation between the compositions. Only the formulations with none or lower amount of $\mathrm{C} 2 \mathrm{C} 8$ are similar at 95\% level.

In our work, it was found that both UTS and elastic modulus decreased with the addition of $\mathrm{C} 2 \mathrm{C} 8$ copolymer and RTP. However, these reductions are not so abrupt compared with the values obtained for neat HDPE, mainly for UTS property. This can be correlated with the developed morphology. SEM images shown that RTP particles are well distributed and dispersed in the polymeric matrix. The decrease in the UTS and elastic modulus values leads to the conclusion that there is lack of interfacial adhesion between the components; however, the decrease in the values of those properties is not abrupt. Besides this observation, toughness of the mixtures is far improved comparing with neat HDPE, even for great concentrations of RTP.

According to Raman coupled to optical microscopy analyses, $\mathrm{C} 2 \mathrm{C} 8$ is not placed in the interface and does not behavior as compatibilizer. Due to the chemical affinity, it is dispersed in HDPE matrix. Thus, the development of the mechanical properties can be attributed not to the interfacial properties between the components, but to the elastomeric contribution of $\mathrm{C} 2 \mathrm{C} 8$ to the mixture. It is expected that rubber components presents lower elastic modulus and tensile strength and much higher toughness than others polymeric materials. These $\mathrm{C} 2 \mathrm{C} 8$ features are exactly tranfered to the mixtures with HDPE and RTP.

The deterioration of elastic modulus and ultimate tensile strength is widely compensated by the increase in impact strength provided by the addition of any concentration of C2C8 and RTP above $30 \%$. This is an interesting outlook because the use of RTP, which is a waste widely find in landfills as well as in the whole environment can be useful when added to polymeric matrix as reinforcement, taking advantage of the value aggregated by the fillers present in the tire rubber, like carbon black. The addition of elastomeric copolymer, like $\mathrm{C} 2 \mathrm{C} 8$, even in little concentrations can provide significant improvements on mechanical properties, mainly impact strength.

\section{Conclusions}

Scanning electron microscopy showed a miscible blend between HDPE and C2C8. Raman spectroscopy coupled to optical microscopy revealed that HDPE phase encapsulates RTP particles instead of $\mathrm{C} 2 \mathrm{C} 8$. For binary mixtures, the impact strength improved with the addition of $\mathrm{C} 2 \mathrm{C} 8$ in HDPE matrix, but great concentrations of RTP gives rise to little increase in this property when it is compared with neat HDPE. The ternary mixtures presented intermediate behavior between binary compositions. Comparison with neat HDPE showed that ultimate tensile strength (UTS) presented a decrease with the concentration of $\mathrm{C} 2 \mathrm{C} 8$ because it present lower UTS value on its neat form, whereas RTP do not present suitable interfacial adhesion. Elastic modulus showed the same behavior as UTS and decreased with $\mathrm{C} 2 \mathrm{C} 8$ and RTP concentration comparing with pure HDPE. For these properties, the ternary mixtures presented intermediate values between binary compositions. Statistical Tukey test were able to give an insight about conditions similarities. In general, the use of RTP in HDPE matrix can be an advantageous alternative to recycle that component.

\section{Acknowledgements}

The authors would like to thank Branskem, Dow and Presidente Recapagem for the donation of the materials used in this research. The finantial support provided by Capes, $\mathrm{CNPq}$ and Fundação Araucária is also acknowledged.

\section{References}

1. Adhikari, B.; De, D. \& Maiti, S. - Prog. Polym. Sci., 25, p.909 (2000). http://dx.doi.org/10.1016/S0079-6700(00)00020-4

2. Ouyang, C.; Gao, Q.; Shi, Y. \& Shan, X.-J. - Appl. Polym. Sci., 123, p.485 (2012). http://dx.doi.org/10.1002/ app. 34634 .

3. Zhang, X.-X.; Lu, C.-H. \& Liang, M.-J. - Appl. Polym. Sci., 103, p.4087 (2007). http://dx.doi.org/10.1002/app.25510.

4. Laganinhos, C. A. \& Tenório, J. A. S. - Polímeros, 18, p.106 (2008)

5. Rooj, S.; Basak, G. C.; Maji, P. K. \& Bhowmick, A. K. - J. Polym. Environ., 19, p.382 (2011). http://dx.doi.org/10.1007/ s10924-011-0293-5.

6. Scuracchio, C. H.; Waki, D. A. \& Bretas, R. E. S. Polímeros., 16, p.46 (2006). http://dx.doi.org/10.1590/ S0104-14282006000100011.

7. Tsuchii, A. \& Tokiwa, Y. - J. Polym. Environ., 13, p.75 (2005). http://dx.doi.org/10.1007/s10924-004-1231-6.

8. Tsuchii, A. \& Tokiwa, Y. - J. Polym. Environ., 14, p.403 (2006). http://dx.doi.org/10.1007/s10924-006-0026-3.

9. Mélo, T. J. A.; Pinheiro, L. A. \& Canevarolo, S. - Polímeros, 20 , p.322 (2010). http://dx.doi.org/10.1590/S010414282010005000050 .

10. Selonke, M. M.; Moreira, T. F.; Schafranski, L. L.; Bassani, A.; Carvalho, B. M.; Prestes, R. A.; Pinheiro, L. A. \& Almeida, D. M. - Polímeros., 22, p.491 (2012). http://dx.doi.org/10.1590/ S0104-14282012005000071. 
11. Sonnier, R.; Leroy, E.; Clerc, L.; Bergeret, A.; LopezCuesta, J. M.; Bretelle, A. S. \& Lenny, P. - Polym. Test., 27, p.901 (2008). http://dx.doi.org/10.1016/j. polymertesting.2008.07.003.

12. Ouyang, C.; Gao, Q.; Shi, Y. \& Shan, X. - J. Appl. Polym. Sci., 123, p.485 (2012). http://dx.doi.org/10.1002/ app.34634.

13. Cossa, M. M.; Sirqueira, A. S. \& Soares, B. G. - Polímeros, 19, p.190 (2009)

14. Fan, P. \& Lu, C. - J. Polym. Environ., 19, p.943 (2011). http:// dx.doi.org/10.1007/s10924-011-0352-y.

15. Colom, X.; Cañavete, J.; Carrillo, F. \& Suñol, J. J. - J. Appl. Polym. Sci., 112, p.1882 (2009). http://dx.doi.org/10.1002/ app.29611.

16. Colom, X.; Carrillo, F. \& Cañavete, J. - Compos. Part AAppl. Sci. Manuf., 38, p.44 (2007). http://dx.doi.org/10.1016/j. compositesa.2006.01.022.

17. Colom, X.; Cañavate, J.; Carrillo, F.; Velasco, J. I.; Pagès, P.; Mujal, R. \& Nogués, F. - Eur. Polym. J., 42, p.2369 (2006). http://dx.doi.org/10.1016/j.eurpolymj.2006.06.005.

18. Naskar, A. K.; Bhowmick, A. K. \& De, S. K. - Polym. Eng. Sci., 41, p.1087 (2001). http://dx.doi.org/10.1002/pen.10809.
19. Grigoryeva, O.; Fainleib, A.; Starostenko, O.; Tolstov, A. \& Brostow, W. - Polym. Int., 53, p.1693 (2004). http://dx.doi. org/10.1002/pi.1530.

20. Araújo, E. M.; Carvalho, L. H.; Fook, M. V. L. \& D’Almeida, J. R. M. - Polímeros., 7, p.45 (1997). http://dx.doi.org/10.1590/ S0104-14281997000300008.

21. Ahmed, S. \& Jones, F. R. - J. Mater. Sci., 25, p.4933 (1990). http://dx.doi.org/10.1007/BF00580110.

22. Ferrer-Giménez, C.; López-Martínez, J.; Nadal-Gisbert, A.; Cuerda-Correa, E. M. \& Macías-García, A. Plast. Rubber. Comp., 38, p.195 (2009). http://dx.doi. org/10.1179/174328909X388026.

23. Millen, R. P.; Faria, D. L. A. \& Temperini, M. L. A. - Quim. Nova, 28, p.289 (2005). http://dx.doi.org/10.1590/S010040422005000200021.

24. Lotti, C.; Correa, C. A. \& Canevarolo, S. V. - Mater. Res., 3, p.37 (2000). http://dx.doi.org/10.1590/S151614392000000200007 .

Received: Nov. 11, 2013

Revised: May 28, 2014 Accepted: June 06, 2014 